\title{
Effect of Polarized Light Therapy on Hair Regrowth in Alopecia Areata
}

\author{
HEBA A. EID, M.Sc.*; MOHAMED M. KHALAF, Ph.D.*; HEBA M. DIAB, M.D.** and \\ WALID A. ABOUEL-NAGA, Ph.D.* \\ The Department of Physical Therapy for Surgery, Faculty of Physical Therapy, Cairo University, Giza* and \\ The Department of Plastic Surgery, Faculty of Medicine, Ain Shams University**, Egypt
}

\begin{abstract}
Background: Polarized light has a lot of uses and in this study I use it to help patients with alopecia areata ti regain their hair.

Aim of Study: To determine the effect of polarized light therapy on ptients with Alopecia Areata.

Material and Methods: 7-point assessment scale and hair counting.

Thirty patients (male and female) with ages ranging from 18-35 years suffering from alopecia areata participated in this study. They were selected randomly from Cairo University Hospitals, they were randomly divided into 2 equal groups in number, one study Group (A) and a control one (B). The control Group (B) who not received the polarized light therapy (Bioptron light therapy) but they just received minoxidil, and they were instructed about their nutrition, the study Group (A) who received the polarized light therapy (Bioptron light therapy) for 10 minutes every session, application was done 2 times per week for 2 months as a total period of treatment. Measurements were conducted before starting the treatment as a first record and at the end of the second month of treatment as a second (final) record.
\end{abstract}

Results: Result showed that the polarized light therapy was effective and fruitful in increasing hair regrowth in alopecia as evidenced by the highly significant increase in the 7-point assessment scale and hair counting.

Conclusion: Polarized light therapy is beneficial in improving hair regrowth in alopecia.

Key Words: Polarized light therapy - Alopecia areata - Hair regrowth.

\section{Introduction}

ALOPECIA Areata (AA) is a common disease of non scarring alopecia including the scalp and/or body, characterized by hair loss without any clinical inflammatory signs. It is one of the most common

Correspondence to: Dr. Heba A. Eid, The Department of Physical Therapy for Surgery, Faculty of Physical Therapy, Cairo University, Giza, Egypt form of hair loss seen by dermatologists and accounts for $25 \%$ of all the alopecia cases. Both males and females are equally affected and it can occur at any age, the highest prevalence age was between $30-59$ years [1]

The etiology of AA is attributed to an autoimmune process, which may be modified by genetic factors and aggravated by emotional stress. Many studies have reported an abnormal cell-mediated immune reaction in AA. There is an increased suppressor T-cell function in patients experiencing hair regrowth [2].

Alopecia areata usually presents as patches of hair loss on the scalp but any hair-bearing skin can be affected. The involved skin may be slightly reddened but otherwise appears normal. Short broken hairs (exclamation mark hairs) are frequently seen around the edges of expanding patches of alopecia areata. The nails are affected in about $10 \%$ of patients referred for specialist advice. It may present as single or multiple patches. Small distinct patches may merge and form larger patches. Scalp is the most common site (90\%) [3] .

\section{Material and Methods}

In New Cairo Hospital for two months, the patients were randomly assigned into two equal groups (15 patients of each group) (study and control groups). Group (A): The study group received linear polarized light, in addition to the Minoxidile the application of the polarized light 4-10min, 3 times per week and for three months with a gap of about 2 days between each session Group (B): The controlled group received only medical care (minoxidile) for alopecia areata. 


\section{Inclusive criteria included:}

Patients were of both sexes (males and females). Age of the patients ranged from 18 to 35 years. The lesion involved less than $20 \%$ of the scalp or beard.

\section{Exclusive criteria included:}

Patients who had been treated using chemo or radiotherapy. Patient who had associated disorders, pregnancy immunodeficiency, HIV, diabetes or anemia, patients suffered from mental or psychological disorders. Patients suffered from any systemic diseases that may interfere with the objectives of the study.

\section{Ethics:}

The protocol of this study was approved by the Ethical Committees of the Faculty of Physical Therapy (Cairo University, Egypt). Every patient applied informed consent before starting the study. All participants were informed about the nature and the effect of the treatment and measurement devices. The patients were also instructed to report any side effects during the treatment sessions.

\section{Measurements:}

\section{A- 7-point assessment scale:}

Global photographs were assessed versus the baseline global photgraphs using the same 7-point rating scale.
Global photographs for each patient were taken before and after Bioptron application. These global photgraphs were assessed versus the baseline global photographs using the same 7-point rating scale [4].

\begin{tabular}{lc}
\hline Greatly decrease & -3 \\
Moderately decrease & -2 \\
Slightly decrease & -1 \\
No change & 0 \\
Slightly increase & +1 \\
Moderately increase & +2 \\
Greatly increased & +3 \\
\hline
\end{tabular}

\section{B- Hair counting:}

Hair count was measured in a 1-inch-diameter determined circular area centered at the leading edge of the area of thinning. Hair-count data were obtained from macrophotographs of the area by converting all visible hairs in the macrophotographs to do maps. The hair in the dot map were counted using computer-assisted image analysis, which detected only "non-vellus-like/miniaturized" hairs. Thus, hair counts measured only "cosmetically significant" hairs. Hair counts were assessed by the difference between the count at each time point versus the baseline count, and the mean hair count values for each treatment group were determined using least squares means [4].
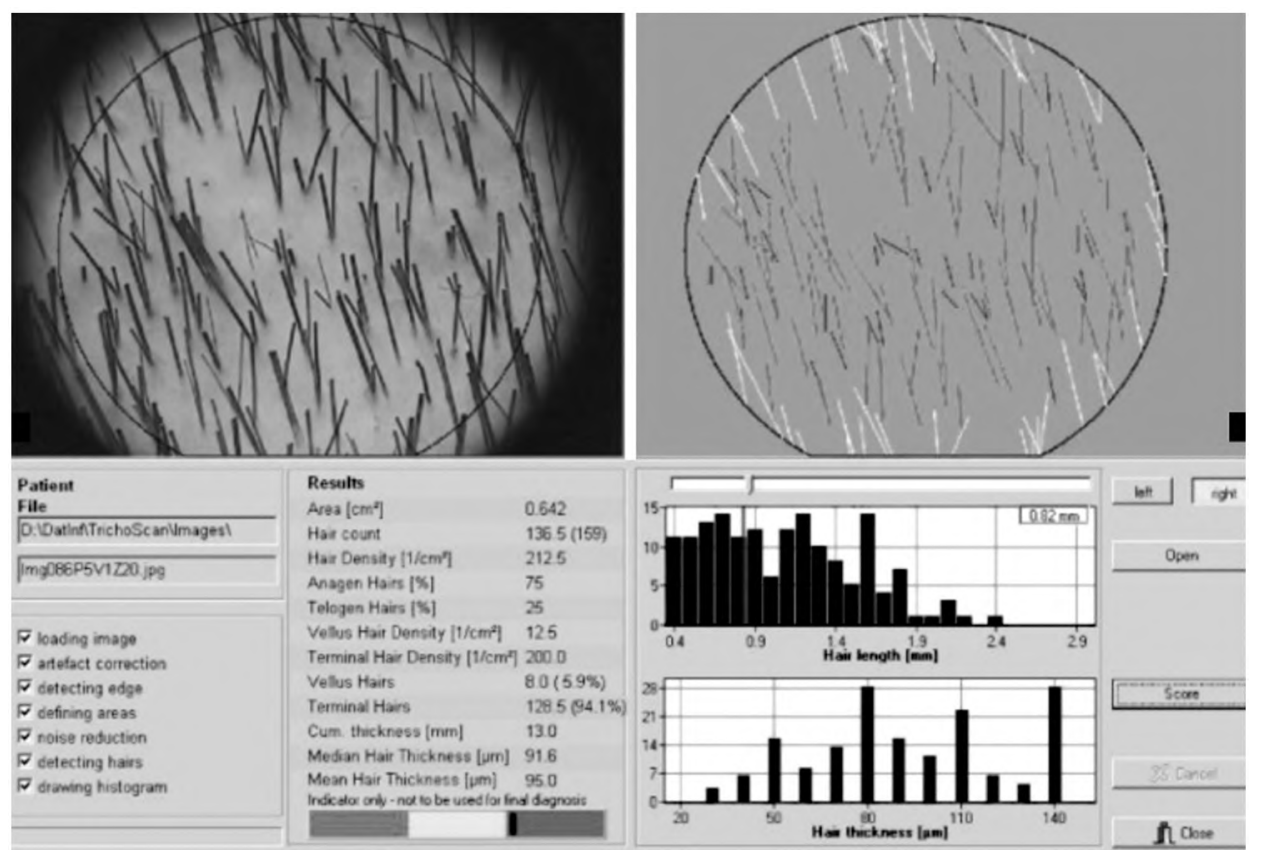

Fig. (1): The figure illustrates a digital image taken at 20-fold magnification (left side of the image) and shows the area of $0.65 \mathrm{~cm} 2$ (blue circle), which is analyzed with the Tricho Scan Software. The Tricho Scan results are illustrated on the right side, where the detected hairs are illustrated with different colors. Red hairs are nongrowing hairs (telogen), green hairs are growing hairs (anagen), and yellow hairs touch the borders of the circle. The right lower part of the figure shows a histogram of the different hair lengths detected by the Tricho Scan Software. Furthermore, the cumulative hair thickness and number of terminal and vellus hairs is calculated [5] 


\section{Treatment procedures:}

Group A (experimental group) subjects were comfortably seated in a chair with back support and feet on the floor, the areas of skin to be treated of the scalp was cleaned with soap and water, the plug of the polarized light unit was inserted into the main current supply, irradiation was carried out with the SL using a B-type lens unit at a setting of $1.26 \mathrm{~W}$, with 4-s pulses delivered at 1-s intervals. Probes were attached to the lesional skin for 10 min three time per week for 3 months.

Group B (control group) were received only medical care (minoxidile) for alopecia areata.

\section{Statistical procedures:}

Descriptive statistics and $t$-test were conducted for comparison of subject characteristics between both groups. $t$-test was conducted to compare mean values of hair count between both groups. Paired $t$-test was conducted to compare between pre and post-treatment mean values of hair count in each group. Mann-Whitney U-test was conducted for comparison of median values of 7-point assessment scale between both groups. Wilcoxon signed ranks test was conducted for comparison of median values of 7-point assessment scale between pre and post treatment in each group. The level of significance for all statistical tests was set at $p<0.05$. All statistical tests were performed through the Statistical Package for Social Sciences (SPSS) Version 19 for windows (IBM SPSS, Chicago, IL, USA).

\section{Results}

\section{Subject characteristics:}

Table (1) showed the mean \pm SD age of study and control groups. There was no significant difference between both groups in the mean age ( $p=$ $0.71)$.

Table (1): Comparison of subject characteristics between study and control groups.

\begin{tabular}{lccccc}
\hline & \multicolumn{2}{c}{$\mathrm{X} \pm \mathrm{SD}$} & & $\begin{array}{c}t- \\
\text { value }\end{array}$ & $\begin{array}{c}p- \\
\text { value }\end{array}$ \\
\cline { 2 - 5 } & Study group & Control group & & & \\
\hline Age (years) & $26.33 \pm 4.98$ & $27 \pm 5.05$ & -0.67 & -0.36 & $0.71^{*}$ \\
\hline $\bar{X} \quad$ : Mean. & & $p_{*}$-value : Probability value. \\
SD : Standard Deviation. & & & : Non significant. \\
MD : Mean Difference. & & & &
\end{tabular}

\section{- Within group comparison:}

There was a significant increase in hair count post-treatment in study and control groups compared with that pre-treatment $(p=0.0001)$ (Table 2), Fig. (2).
There was a significant increase of 7-point assessment scale post treatment in study and control groups compared with that pre-treatment ( $p=$ 0.0001 ) (Table 3).

Table (2): Comparison of hair count between pre and posttreatment in study and control groups.

\begin{tabular}{|c|c|c|c|c|c|}
\hline \multirow[b]{2}{*}{ Hair count } & \multicolumn{2}{|c|}{$\bar{X} \pm \mathrm{SD}$} & \multirow[b]{2}{*}{ MD } & \multirow{2}{*}{$\begin{array}{c}t- \\
\text { value }\end{array}$} & \multirow{2}{*}{$\begin{array}{c}p- \\
\text { value }\end{array}$} \\
\hline & $\begin{array}{c}\text { Pre- } \\
\text { treatment }\end{array}$ & $\begin{array}{l}\text { Post- } \\
\text { treatment }\end{array}$ & & & \\
\hline Study group & $0 \pm 0$ & $107.86 \pm 20.6$ & -107.86 & -20.27 & $0.0001 * *$ \\
\hline Control group & $0 \pm 0$ & $64.46 \pm 5.08$ & -64.46 & -49.11 & $0.0001 * *$ \\
\hline
\end{tabular}

Comparison of hair count between study and control groups pre and post-treatment.

\begin{tabular}{lllllll}
\hline \multirow{2}{*}{ Hair count } & \multicolumn{2}{c}{$\mathrm{X} \pm \mathrm{SD}$} & & $\begin{array}{c}t- \\
\text { value }\end{array}$ & $\begin{array}{c}p- \\
\text { value }\end{array}$ \\
\cline { 2 - 5 } & Study group & Control group & & & \\
\hline Pre-treatment & $0 \pm 0$ & $0 \pm 0$ & 0 & - & - \\
Post-treatment & $107.86 \pm 20.6$ & $64.46 \pm 5.08$ & 43.4 & 7.92 & $0.0001^{* *}$ \\
$\bar{X} \quad$ : Mean. & & $p_{* *}$-value : Probability value. \\
SD : Standard Deviation. & & & & Significant. \\
MD : Mean Difference. & & &
\end{tabular}

Table (3): Comparison of 7-point assessment scale between pre and post-treatment in study and control groups.

\begin{tabular}{lcccc}
\hline 7-point & \multicolumn{2}{c}{ Median } & $\begin{array}{c}\text { Z- } \\
\text { assessment scale }\end{array}$ & $\begin{array}{c}p \text { - } \\
\text { value }\end{array}$ \\
\cline { 2 - 5 } & Pre-treatment & Post-treatment & & \\
\hline Study group & -3 & +1 & 3.57 & $0.0001^{* *}$ \\
Control group & -2 & -1 & 3.49 & $0.0001^{* *}$ \\
\hline$p$-value: Probability value. & $* *$ : Significant.
\end{tabular}

Comparison of 7-point assessment scale between study and control groups pre and post-treatment.

\begin{tabular}{lcccc}
\hline 7-point & \multicolumn{2}{c}{ Median } & U- & $\begin{array}{c}p- \\
\text { assessment scale } \\
\text { value }\end{array}$ \\
\cline { 2 - 5 } & Study group & Control group & value & \\
\hline Pre-treatment & -3 & -2 & 97.5 & $0.47^{*}$ \\
Post-treatment & +1 & -1 & 4.5 & $0.0001^{* *}$ \\
\hline$p$-value: Probability value. *: Non significant. & & $* *$ : Significant.
\end{tabular}

\section{- Comparison between groups:}

Comparison between study and control groups post-treatment revealed a significant increase in hair count of study group compared with that of control group $(p=0.0001)$.

There was no significant difference in 7-point assessment scale between study and control groups pre-treatment $(p=0.47)$. While, there was a significant increase in 7-point assessment scale of study group post-treatment compared with that of control group $(p=0.0001)$. 


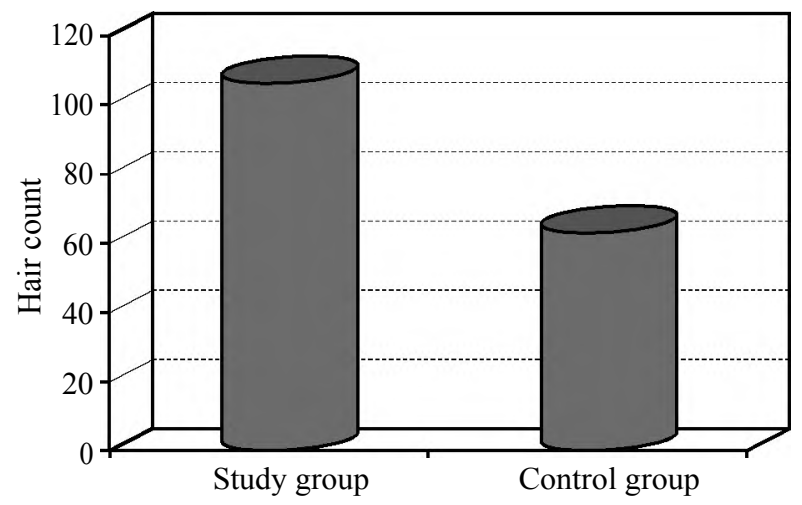

Fig. (2): Mean values of hair count of study and control groups pre and post-treatment.

\section{Discussion}

Hair has many useful biologic functions, including protection from the elements and dispersion of sweat gland products (e.g., pheromones) [6]. It also has psychosocial importance in our society, and patients with hair loss (alopecia) or excessive hair growth often suffer tremendously [7]. Not surprisingly, the demand for drugs that alter hair growth and appearance has led to a multibilliondollar industry, yet few drugs that are effective for these purposes are available [8]. However, recent progress in our understanding of the biology and pathology of hair follicles should lead to more effective therapies for disorders of hair growth [9]

Hair follicles undergo repetitive regenerative cycles and each of these cycles consists of three stages: Anagen (rapid growth, active stage), catagen (apoptosis-driven regression, physiological involution stage), and telogen (resting stage). Bulge stem cells are found in the region of the outer root sheath located just below the sebaceous gland, coinciding with the point of anchorage of the arrector pili muscle [10].

During the telogen to anagen transition, there is a tightly controlled activation of these epithelial bulge stem cells and within the same period, secondary hair germ cells give rise to Transient Amplifying (TA) progeny cells [11].

Throughout the entire anagen phase, there is a robust proliferation of the TA cells within the epithelial matrix of the hair follicle. Consequently, proliferating trichocytes terminally differentiate to form the bulk of the hair filament which is the final product of the hair cycle. The dermal papilla of the hair follicle is believed to be the key regulatory element in progenitor cell activation, hair matrix cell proliferation and terminal differentiation of trichocytes [12].
Transient activation of the pathway in this layer is sufficient to initiate the anagen phase, during the catagen follicular involution phase, a rapid regression of perifollicular blood vessels is associated with downregulation of follicular VEGF expression [13].

The telogen phase is the resting stage of the growth cycle. The hair shaft may be easily dislodged during the telogen phase and often will fall out. Near the end of the telogen phase, an intermediate phase begins and a new follicle forms from the remainder of the follicle of the previous hair cycle. After this formation, a new hair forms and the anagen phase starts again. The new hair shaft normally will push out old hair remaining from the previous cycle, but occasionally two hairs (one from the previous cycle and one from the current cycle) will protrude from a single canal [14].

Polarized light therapy, a kind of phototherapy, is a linearly polarized and polychrome light therapy. This light therapy contains a whole spectrum of visible rays, infrared A and B rays as well. Polarized light comes from refraction of common light through the specific laminated mirrors and admitted this light through photo filter system. Biologic effects of this physical modality are well known: Enhancement of the cell membrane activities, acceleration of the production of the Adenosine Triphosphate (ATP) in mitochondria, return to normal cell membrane potential which was disturbed, stimulation of the regenerative processes. Additionally, fibroblast proliferation and deposition of collagen could be accelerated by this kind of physical therapy. These, so-called cellular and subcellular polarized light effects are the base of systemic polarized light effects: Improving microcirculation, diminishing inflammation, improving tissue oxygenation, enhancing of the wound healing, accelerating epithelialisation of wound and improving quality of early scar tissue formation [15] .

Results of this study concerning the efficacy of polarized light and in hair regrowth in patient with alopecia areata that observed and recorded by (Mowafy et al., [16]; Allam, [17], Shukla et al., [18]; Mark et al., [19]; Hawkins and Abrahamse [20] Pejcic et al., [21]; Fenyo et al., [22]; Pinar et al., [23] .

Mowafy et al., [16] reported that there is nonsignificant difference in the pre-treatment records of the 7-point assessment scale and hair counting, between the mean values of the study and the control groups. Results of this study revealed a 
highly significant increase in the mean values of the 7-point assessment scale and hair counting in the study group after the application of polarized light therapy, also comparing second records of the 7-point assessment scale and hair counting, between the mean values of the study and the control groups showed highly significant increase indicating that polarized light therapy was fruitful and beneficial in increasing hair regrowth in alopecia as evidenced by the highly significant increase in the 7-point assessment scale and hair counting.

Allam, [17] reported that evaluated the efficacy of the low level laser therapy on hair regrowth in alopecia. 30 male and female patients with androgenic alopecia and alopecia areata were divided into two groups: Control Group (A) received nutrition, instructions and no laser and study Group (B) received nutrition, instructions and laser application. Results of the study showed that low level laser therapy had variable and fruitful effects on the hair regrowth in alopecia as evidenced by the highly significant Increases in frontal, vertex and temporal 7-PAS and hair count.

Shukla et al., [18] reported that He-Ne laser irradiation (at $\mathrm{I} \mathrm{J} / \mathrm{cm}^{2}$ ) of the skin of both the control and the testosterone-treated mice was observed to lead to a significant increase $(p 0.05)$ in $\%$ of anagen, indicating stimulation of hair growth In mice. Both histology and Optical Coherence Tomography (OCT) were used for the measurement of hair follicle length and the relative percentage of hair follicle in different growth phases.

Mark et al., [19] mentioned that the mechanism of action by which photobiomodulation stops or reverse male or female pattern hair loss is unknown. Multiple theories exist to explain the observed changes which occur on a cellular level in response to low level laser therapy. One theory suggests an increased blood flow at the dermal papilla as a possible mechanism of action. Clinical examples of photo-induced hair growth include the paradoxical growth of hair that occurs in a small percentage of patients undergoing laser hair removal and PUVA to treat alopecia areata treatment protocols include 15-30 minute treatment on alternating days for 2-4 weeks, tapering to one to two treatments per week for 6-12 months, followed by bi-weekly and once per month maintenance treatment.

Hawkins and Abrahamse, [20] reported that phototherapy plays an important role in stimulating living cells. This phenomenon is potentially useful as a therapeutic mechanism, and has already been used for several therapeutic purposes such as wound healing and inflamed acne.

Pejcic et al., [21] reported that a low Level Polarized Polychromatic noncoherent Light (LPPL) was proven to have anti-inflammatory effect on chronic tendonitis and gingivitis in several reports. Others demonstrated that the exposure of a small area of the human body to LPPL (480-3, 400nm, $12 \mathrm{~J} / \mathrm{cm}^{2}$ ) decreased in the elevated pro-inflammatory cytokine levels and increased in the antiinflammatory factor concentration. The decrease of proinflammatory cytokine such as TNF- $\alpha$, IFN$y$, and IL-2 and anti-inflammatory effect after LPPL exposure may pose a suitable explanation of the clinical result of LPPL in the inflammatory skin disease.

Fenyo et al., [22] reported that polarized light applied in vitro (in contrast with similarly used diffuse light) enhanced immunoglobulin $\mathrm{M}$ (IgM) synthesis in a human B cell line due to an increased local IL-6 production and autocrine effect by B cells. At the same time, its effect inhibited significantly IL-6 production in monocytes regulating numerous pro-inflammatory mediators. This effect suggests that reducing inflammation (i.e., impaired IL-6 production by monocytes) and enhancing the active immune response (i.e., stimulation of $\mathrm{B}$ and T lymphocytes). In the monocyte cell culture the effect of LPL in the constitutive secretion of IL6 and the secretion. The effect of medium alone, $1 \propto \mathrm{g} / \mathrm{ml}$ LPL (low polarized light) or $5 \propto \mathrm{g} / \mathrm{ml}$ LPL. On the production of IL- 6 by human peripheral monocytes after $48 \mathrm{~h}$, previously exposed to LPL and DL (diffuse light) for 0-300s. Means of six experiments \pm Standard Error of Mean (SEM) values are demonstrated. Without LPS, exposure of a monocyte monolayer to LPL or DL for a duration of between 5 and $300 \mathrm{~s}$ induced no significant change in the constitutive IL-6 production. However, we observed a very pronounced decrease in the secretion of IL-6 in experiments after stimulation with a sub-optimal dose of LPL $(1 \propto \mathrm{g} / \mathrm{ml})$ followed the exposure to LPL for a duration of 5 or 30s (reductions of 67 and $85 \%$, respectively).

Pinar et al., [23] reported that A Low-Level Laser Light Therapy (LLLT) is a fast-growing technology used to treat a multitude of conditions that require stimulation of healing, relief of pain and inflammation, and restoration of function. Although the skin is the organ that is naturally exposed to light more than any other organ, it still responds well to red and near-infrared wavelengths. The photons are absorbed by mitochondrial chromophores in skin cells. Consequently electron 
transport, Adenosine Triphosphate (ATP) nitric oxide release, blood flow, reactive oxygen species increase and diverse signaling pathways get activated. Stem cells can be activated allowing increased tissue repair and healing. In dermatology, LLLT has beneficial effects on wrinkles, acne scars, hypertrophic scars, and healing of burns. LLLT can reduce UV damage both as a treatment and as a prophylaxis. In pigmentary disorders such as vitiligo, LLLT can increase pigmentation by stimulating melanocyte proliferation and reduce depigmentation by inhibiting autoimmunity and Inflammatory diseases. The non-invasive nature and almost complete absence of side-effects encourages further testing in dermatology.

\section{Conclusion:}

It was concluded that the polarized light is an effective treatment in hair regrowth in alopecia areata.

\section{References}

1- KARYEN S.D., MATTHEW B.M. and DANIEL L.S.: "Common hair disorders". Journal of American Academy of Family Physicians, 68: (93-102-107-8), 2003.

2- WASSERMAN D., GUZMAN-SANCHEZ D.A., SCOTT K. and McMICHAEL A.: "Alopecia areata in the United States: Outpatient utilization and common prescribing patterns". J. Am. Acad. Dermatol., 57: 49-51, 2007.

3- GALÁN-GUTIÉRREZ M., RODRÍGUEZ-BUJALDÓN A. and MORENO-GIMÉNEZ J.C.: "Update on the treatment of alopecia areata" Actas Dermosifiliogr., 100 (5): 266-76, 2009.

4- KAUFMAN D., ELISE A., OLSEN C. and DAVID W.: "Finasteride in the treatment of men with androgenetic alopecia" Journal of the American Academy of Dermatology, 19 (4): 579-89, 2008.

5- ROLF HOFFMANN: "TrichoScan: A Novel Tool For The Analysis of Hair Growth" Journal of Investigative Dermatology, 8 (1): 109-15, 2003.

6- GARZA L., YANG C., ZHAO T., BLATT H., LEE M., HE H., STANTON D., CARRASCO L., SPIEGEL J., TOBIAS J. and COTSARELIS G.: "Bald scalp in men with androgenetic alopecia retains hair follicle stem cells but lacks CD200-rich and CD34-positive hair follicle progenitor cells" The Journal of Clinical Investigation, 121 (2): 613-22, 2011.

7- ABRAHAM M.K.: Scalp anatomy" Journal of Medicine Specialties Otolaryngology and Facial Plastic Surgery, 5 (22): 177-88, 2006

8- McMICHAEL A.: "Excimer Laser: A Module of the Alopecia Areata Common Protocol" Journal of Investigative Dermatology Symposium Proceedings, 1 (6): 577-9, 2013.

9- MONSTREY S., H. HOEKSEMA, K. DEPUYDT, G VAN MAELE, K. VAN LANDUYT and P. BLONDEEL:
"The effect of polarized light on wound healing". European Journal of Plastic Surgery, 24 (8): 377-82, 2002.

10- PLIKUS M., MAYER J., CRUZ D., BAKER R., MAINI P., MAXSON R. and CHUONG C.: "Cyclic dermal BMP signalling regulates stem cell activation during hair regeneration" International Weekly Journal of Science, 45 (1): 340-4, 2008.

11- SHAROV A., TOBIN D., ATOYAN R. and BOTCHKAREV V.: "Changes in Different Melanocyte Populations During Hair Follicle Involution (Catagen)", Journal of Investigative Dermatology, 125 (6): 1259-67, 2005.

12- TIEDEA S., JENNIFER E. KLOEPPERA, B. ENIKÖ BODÓ A., TIWARIC S., KRUSED C. and PAUSA R.: "Hair follicle stem cells: Walking the maze" European Journal of Cell Biology, 8 (6): 355-76, 2007.

13- BAI X., LEI M., SHI J., YU Y.U., BIU W. and LAI X.: "Roles of gosderminA3 in catagen-telogen transition during hair cycling 2015 "Journal of Investigation Dermatology, 135 (9): 2162-72, 2015.

14- WENGRAF D.A., LOWELL T.R. and HULL S.P.: Genetic analysis of autoimmune regulator heliotype in alopecia areata. Journal of Tissue Antigens, Vol. (71) N. (3): 20612, 2008.

15- COLIC M., VIDOJKOVIC' ${ }^{\prime}$ N., JOVANOVIC' ${ }^{\prime} M$. and LAZOVIC' G.: "The Use of Polarized Light in Aesthetic Surgery" aesthetic plastic surgery, 28 (5): 324-7, 2004.

16- MOWAFY Z., ABDEL MONEM M., ABD ALLAH H. and SALAH A.: "effect of polarized light therapy on hair regrowth in alopecia" International Journal of Pharma Techresearch, 9 (10): 40-7, 2016

17- ALLAM: "The involvement of androgens in human hair growth" American Journal of Biomedical Sciences, 1 (9): 37-42, 2003.

18- SHUKLA S., SAHU K., VERMA Y., RAO K.D., DUBE A. and GUPTA P.K.: "Effect of Helium-Neon Laser Irradiation on Hair Follicle Growth Cycle of Swiss Albino Mice" Skin Pharmacology and Physiology, 23 (2): 7985, 2010.

19- MARC R., NICOLE E.: "The use of LLL for Hair Growth" Journal of Cosmetic Laser Therapy, 11 (2): 110-7, 2009.

20- HAWKINS D., HOURELD N. and ABRAHAMSE H.: "Low level laser therapy (LLLT) as an effective therapeutic modality for delayed wound healing". Ann. N. Y. Acad. Sci., 1056: 486-93, 2005.

21- PEJCIC A., KOJOVIC D., KESIC L. and OBRADOVIC R.: The effects of low level laser irradiation on gingival inflammation. Photomed Laser Surg., 28: 69-74, 2010.

22- FENYO M., MANDL J. and FALUS A.: Opposite effect of linearly polarized light on biosynthesis of interleukin6 in a human B lymphoid cell line and peripheralhumanmonocytes. Cell Biol. Int., 26: 265-9, 2002.

23- PINAR A., ASHEESH G., MAGESH S., DANIELA V., ZEEV P., NADAV P. and MICHAEL R.: "Low-Level Laser (Light) Therapy (LLLT) in Skin: Stimulating, Healing, Restoring" Seminars in Cutaneous Medicine and Surgery, 32 (1): 41-52, 2013. 


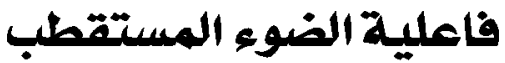

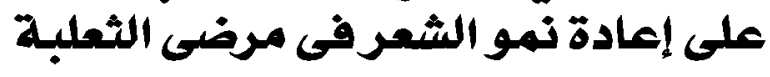

$$
\text { الهدفتحخلص: تطبيق الضوء المستقطب على مرضيى الثعلبة مما يحفز إعادة نمو الثعر. }
$$

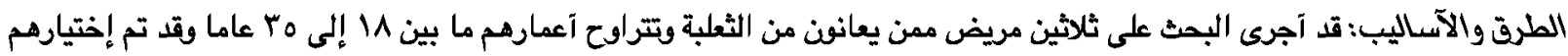

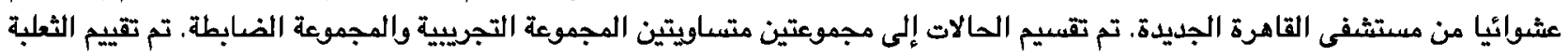

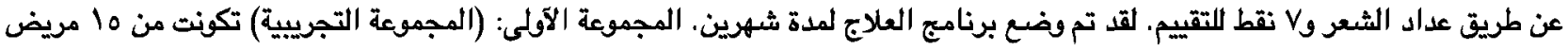

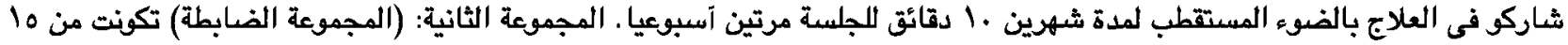
مريض شاركوا بالدواء فقط. مادة المينوكسديل. النتائج:وقد آسفرت التتائج عن وجود دلالة إحصائية لتآثير الضوء المستقطب فى علاج مرضى الثعلبة فى المجموعة التجريبية فى مقابل المجموعة الضابطة.

الخلاصة: من هذه النتائج يمكن إستدلال آن الضوء المستقطب له تآثير مباشر على تحسن الثعلبة. 